\title{
Remediation of the uranium mill tailings pond Dänkritz 2 seismic slope stability analysis and serviceability limit state design
}

\author{
Y Koitzsch CDM Smith, Germany \\ S Klemm CDM Smith, Germany \\ A Muehl CDM Smith, Germany \\ U Barnekow Wismut GmbH, Germany
}

M Speer Wismut GmbH, Germany

\begin{abstract}
The remediation of the East German uranium mining sites operated and used until 1990 started in 1991 and was funded by the German Federal Government. However, most of the numerous abandoned uranium mining sites of third party property that were distributed all over Saxony were not included. In 2003 the Federal Government and the Free State of Saxony agreed to jointly fund the remediation of those abandoned mining sites of high priority. Wismut's department for Project Management of Wismut's Abandoned Saxonian Mining Sites was given the responsibility for the project management. The Dänkritz 2 uranium mill tailings pond is one of those abandoned sites (area: ca. 11 ha; vol. ca. 0.9 Mill. $\mathrm{m}^{3}$ ). Mill tailings were discharged during the 1950s surrounded by a max. $12 \mathrm{~m}$ high autostable ring dam, which was already reshaped during the 1960s to improve geotechnical stability. Dynamic stability calculations, applying the finite element program PLAXIS, were carried out by CDM Smith as part of the remediation design. They resulted in insufficient dynamic stability with respect to the maximum credible earthquake. In addition, soft fine-grained tailings needed to be stabilised to place a multi-layer type surface cover. Wismut designed the tailings remediation project. The paper will particularly focus on the advanced constitutive models used for the slope stability analyses of the embankment under dynamic loads and of the stability of the fine-grained tailings during interim cover placement.
\end{abstract}

\section{Introduction}

In Eastern Germany uranium mining lasted from 1945 until 1990. In total ca. 216,300 t of uranium were produced. The remediation of the uranium mining sites, operated or used until 1990 by the Soviet-German Wismut company, started in 1991 under responsibility of the newly founded Wismut GmbH funded by the German Federal Government. However, most of the numerous abandoned uranium mining sites of third party property, distributed all over Saxony, were not included. In 2003 the Federal Government and the Free State of Saxony agreed to jointly fund the remediation of those abandoned mining sites of high priority. Wismut's department for Project Management of Wismut's Abandoned Saxonian Mining Sites was given the responsibility for the project management. The Dänkritz 2 uranium mill tailings pond is one of those abandoned sites of high priority (area: ca. 11 ha; vol. ca. 0.9 Mill. $\mathrm{m}^{3}$ ). It is located near the city of Zwickau (ca. 91,000 inhabitants). Uranium mill tailings from soda-alkaline leaching were discharged from 1955 until 1958 into Dänkritz 2 tailings pond. It is surrounded by a maximum $12 \mathrm{~m}$ high autostable ring dam, which was already reshaped during the 1960 s to improve geotechnical stability. The radiological, environmental and geotechnical site assessment proved the need for site remediation.

Wismut designed the tailings remediation project and applied for the respective planning approval in 2015. The remediation includes water collection and treatment during remediation, interim covering of sandy 
and soft fine-grained tailings, dam reshaping, re-contouring of the pond area enhancing tailings consolidation by using vertical drains, placement of a multi-layer type final cover, and revegetation.

Geotechnical analyses where carried out by CDM Smith as part of the remediation design with the following aim:

- Prove stability of the ring dam (also taking into consideration earthquake loading).

- Investigate settlements due to consolidation of the tailings, under the load of the overlying re-contour layer and surface cover, to ensure the functionality for the planned runoff diversion system in finale state.

- Prove stability of the interim cover on the fine-grained tailings during placement under the load of the construction equipment.

\section{Site characterisation}

The uranium mill tailings pond, Dänkritz 2, is located in Germany, approximately $8 \mathrm{~km}$ northwest of the city centre of Zwickau. According to DIN EN 1998-1 2010-12 the pond is located in the Earthquake Zone 1 that encompasses areas that are classified at an intensity interval of 6.5 to $<.0$ on the Medwedew-Sponheuer-Karnik-scale, which evaluates the severity of ground shaking on the basis of observed effects in an area of the earthquake occurrence. The design value of soil acceleration $\left(\mathrm{ag}_{\mathrm{g}}\right)$ is $0.4 \mathrm{~m} / \mathrm{s}^{2}$ in Earthquake Zone 1.

The Dänkritz 2 tailings pond has an extension of ca. $250 \mathrm{~m}$ from east to west and ca. $400 \mathrm{~m}$ from north to south. Its area represents approximately 10.5 ha. The tailings pond is located in a former gravel quarry. Between 1955 und 1958 uranium mill tailings from soda-alkaline leaching were discharged into the abandoned open pit. Once the discharge of the tailings exceeded the pit capacity, the coarser particles were piled up to a surrounding ring dam. The heights of this ring dam range between $2 \mathrm{~m}$ (on the west side) and a maximum of $14 \mathrm{~m}$ (on the east side). Slopes of the ring dam show a gradient between 1:2.5 and 1:3 (vertical to horizontal). The basin surrounded by the ring dam is today filled with tailings at thicknesses between $<2 \mathrm{~m}$ (on the west side) and $12 \mathrm{~m}$ (on the east side). In total about 820,000 $\mathrm{m}^{3}$ tailings (without supernatant water) are currently contained in the impoundment, which is partly covered with a supernatant water layer up to a depth of $2 \mathrm{~m}\left(\right.$ ca. $\left.60,000 \mathrm{~m}^{3}\right)$.

Figure 1 shows an aerial view of the Dänkritz 2 tailings pond in 2015. Figure 2 shows an overview map of the Dänkritz 2 tailings pond. The black lines represent the location of two cross-sections presented in Figures 1 and 2 .

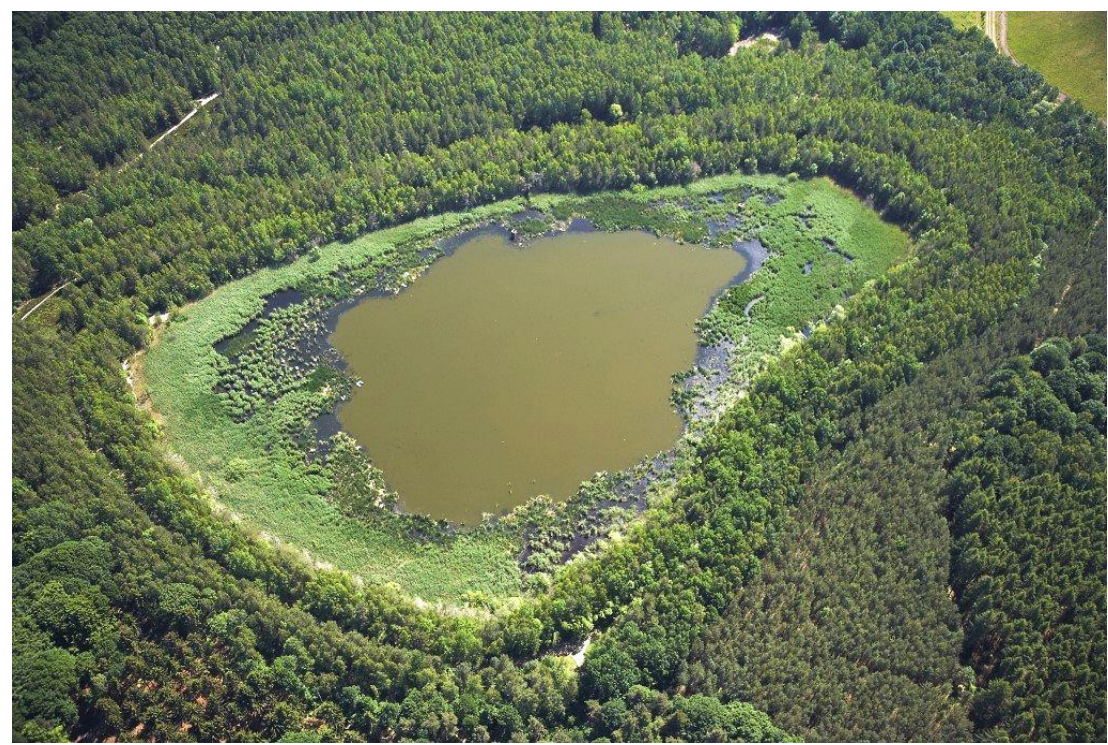

Figure 1 Aerial view on the Dänkritz 2 tailings pond in 2015 (view from northwest to southeast) 


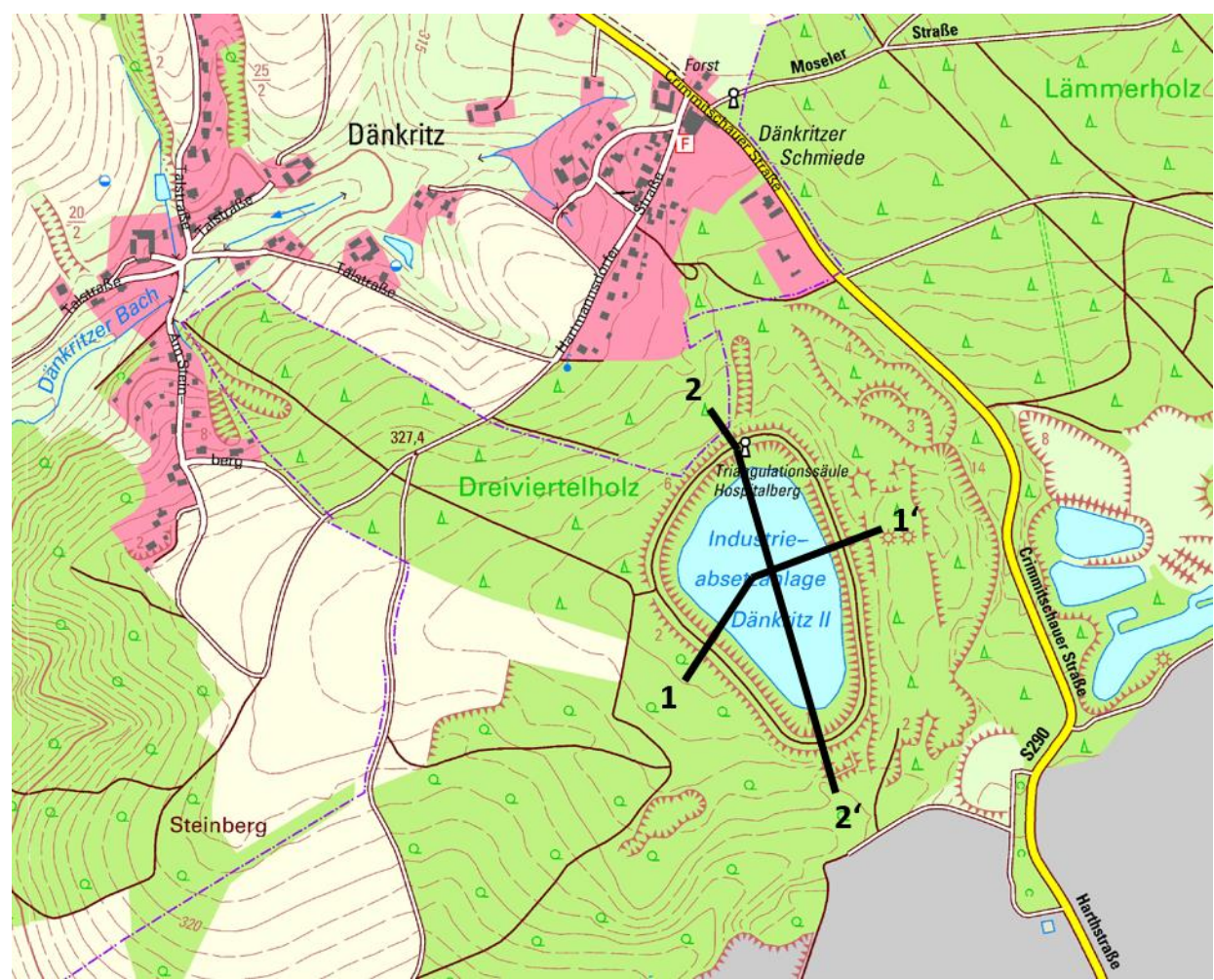

Figure 2 Overview map of the Dänkritz 2 tailings pond

The geogenic subsurface strata of the tailings pond Dänkritz 2 consists of the Rotliegend (Upper Permian), a bedrock which has a weathered zone of approximately $30 \mathrm{~m}$ thickness. The upper $2 \mathrm{~m}$ of the weathered zone includes 10 to $15 \%$ impermeable kaolinite. The Rotliegend is covered by tertiary gravels. On the eastern and southern side of the tailings pond a silt layer with a thickness of $3 \mathrm{~m}$ is enclosed in these gravels. The tertiary gravels were extracted during the working process of the gravel quarry so that there are just 2 to $10 \mathrm{~m}$ left. Quaternary sediments are not important in the area of Dänkritz 2.

\section{Stability for the ring dam}

\subsection{Implementing risks from earthquakes}

There are various standards and regulations that have to be complied with in Germany (although they have been superseded by European standards). For instance, DIN 4149 was often used even for the seismic design of tailing ponds, even though they were developed for multi-storey structures. This standard made it possible to derive representative soil acceleration by categorising earthquake zones and classes of subsoil. Nowadays the seismic design of structures has to be carried out according to the European standard Eurocode 8. Furthermore, for the seismic design of remediation ponds as sedimentation basins the German standard for the design of dam structures (DIN 19700-15) has to be considered.

According to Eurocode 8 (DIN EN 1998-1), Germany is divided into Earthquake Zones 0 to 3 where the subsoil situation (i.e. bedrock, weathered zone) will be considered separately. On a global scale, the earthquake hazard potential in Germany is relatively small, but it still exists. According to DIN 19700-15 the earthquake design should be distinguished between operating basis earthquake design and safe-shutdown earthquake design. The operational basis earthquake has a probability of occurring every 500 years and is the basis for serviceability limit state design. In contrast, the safe-shutdown earthquake is the basis for ultimate limit state design, it has a probability of occurring every 10,000 years (maximum credible earthquake). For all practical purposes, dynamic effects are set in stability calculations in the form of quasi-static alternative loads (as multiples of gravitational acceleration, $g=9.81 \mathrm{~m} / \mathrm{s}^{2}$ ) or as genuine dynamic load (rate of time/acceleration). Substantial acceleration quantities are derived from seismological 
studies. Finally, there are maps for peak acceleration including their probability of occurrence (Figure 3). The German Research Centre for Geoscience (GFZ) in the city of Potsdam provides them in Germany.

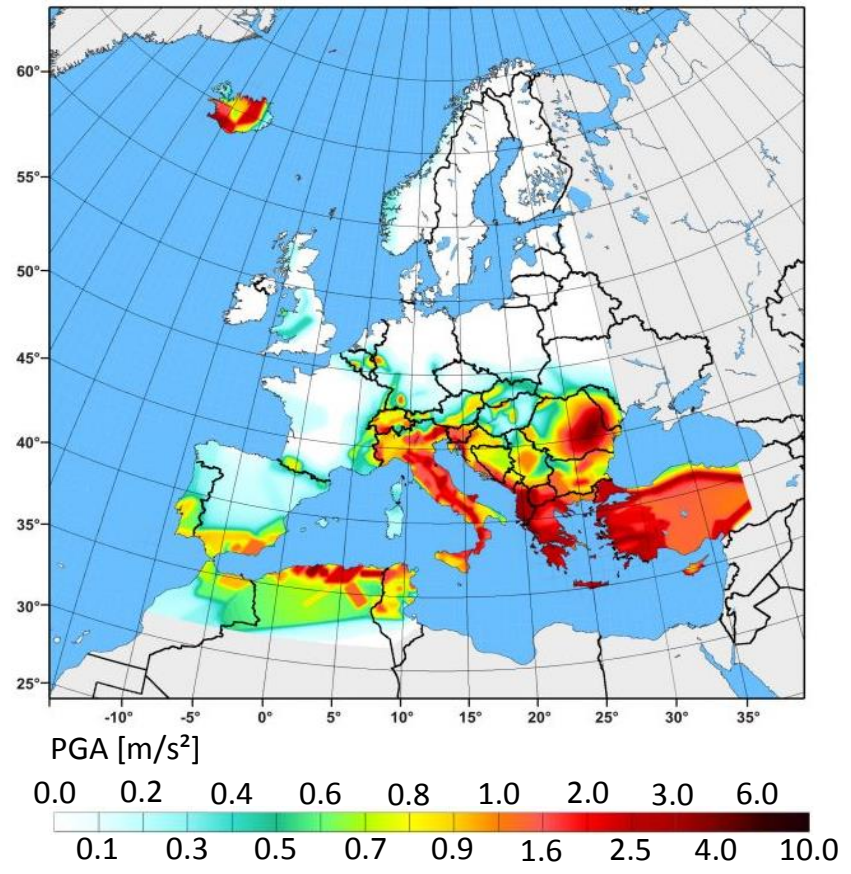

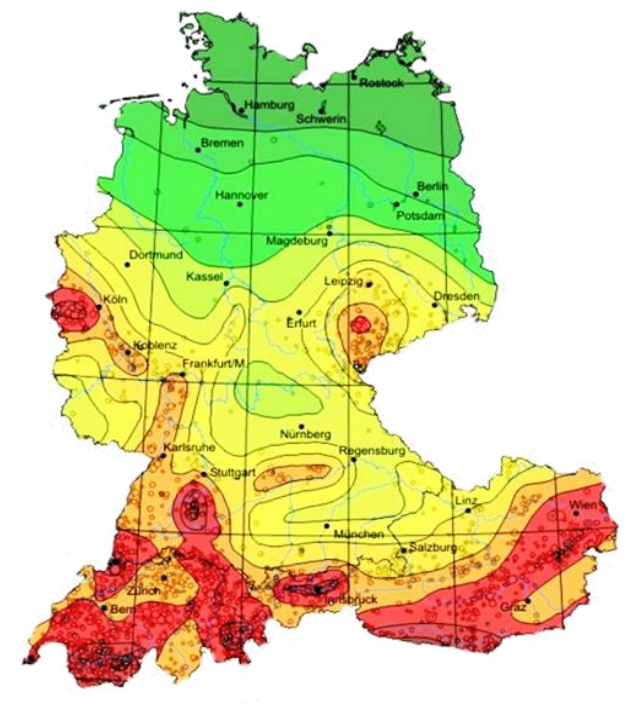

macroseismic intensities

(european macroseismic scale, EMS)

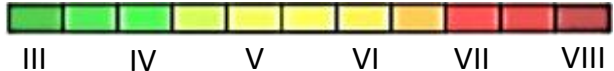

Figure 3 The hazard potential for Europe and macroseismic intensities in Germany (German Research Centre for Geoscience)

Representative rates of time/acceleration are taken from international sources and databases such as the Pacific Earthquake Engineering Research Center, the National Oceanic and Atmospheric Administration, the U.S. Geological Survey, the National Strong-Motion Project, the Global Seismic Hazard Assessment Program and the European Strong-Motion Database. The representative safe-shutdown earthquake was derived in an expert seismological opinion for the Wismut locations from an analysis of historical events in the immediate vicinity of these locations and it corresponds to the progress of an earthquake that occurred in the North Italian region of Friuli in May 1976.

\subsection{Calculation procedures}

In order to analyse slope stability under the influence of earthquakes it is common to implement the earthquake load as a quasi-static load. Design values of acceleration are derived based on the Earthquake Zone and multiplied with importance factors and subsoil parameters. Unfortunately, quasi-static calculations have the drawback that they only take the effective values of soil acceleration into account, while the spread of negative and positive acceleration of the earthquake is not considered. In other words, they do not realistically map the effect that they have on the slope stability occurring in connection with earthquake loads. This is the reason why quasi-static analyses were not done as part of the study, but rather fully dynamic calculations. Fully dynamic calculations differ from the aforementioned approaches and in general they require substantially more time and effort. This method allows to extract acceleration curves (accelerograms) from expert seismological opinions, representative for the location, and use them in coupled calculations. These calculations are based on the finite element method applied in the program PLAXIS. The dynamic tool of PLAXIS was used to analyse the propagation of waves through the soil and their impact on slope stability. This module uses the time integration method where a dynamic signal is broken down into a defined number of small time steps (time increments). Then the system's current stress is obtained for each time increment, using the results of the previous time increment (displacement, velocity and acceleration) as the initial input value. This allows to analyse the system's stress for each time increment and, as an example, extract all time increments in a sequential recording (video). 
The calculations were completed applying a horizontal and a vertical acceleration of the safe-shutdown earthquake as a seismic input motion corresponding to the accelerogram on the base of the model. The calculations were repeated while reducing the parameters $\tan \varphi^{\prime}$ and $c^{\prime}$ until a continuous sliding surface, characterising a slope failure, could be observed by analysing plastic failure points. The factor of safety for the slope was determined by the ratio of shear strength, at this accordingly observed failure, to the available shear strength using Fellenius's law (Fellenius 1936).

\subsection{The numerical model}

The analyses were completed on two two-dimensional model sections (refer to Figure 2). The first cross-section cuts through the tailings pond in the west-eastern orientation. The second cross-section intersects the tailings pond in the north-south orientation. These cross-sections were generally discretised with fifteen-node, triangular, iso-parametric, plane strain elements, allowing fourth-order interpolation and area integration. They are particularly useful in non-linear analysis to determine collapse of soil structures. The finite element mesh was refined to ensure the seismic waves propagated through each element.

Figure 4 shows the numerical model for the slope on the eastern side of the ring dam. It is an extract of the numerical cross section $1-1^{\prime}$, which is about $540 \mathrm{~m}$ long. In the numerical model the layer thickness of the underground is about $30 \mathrm{~m}$. The bottom of the model implies the bedrock.

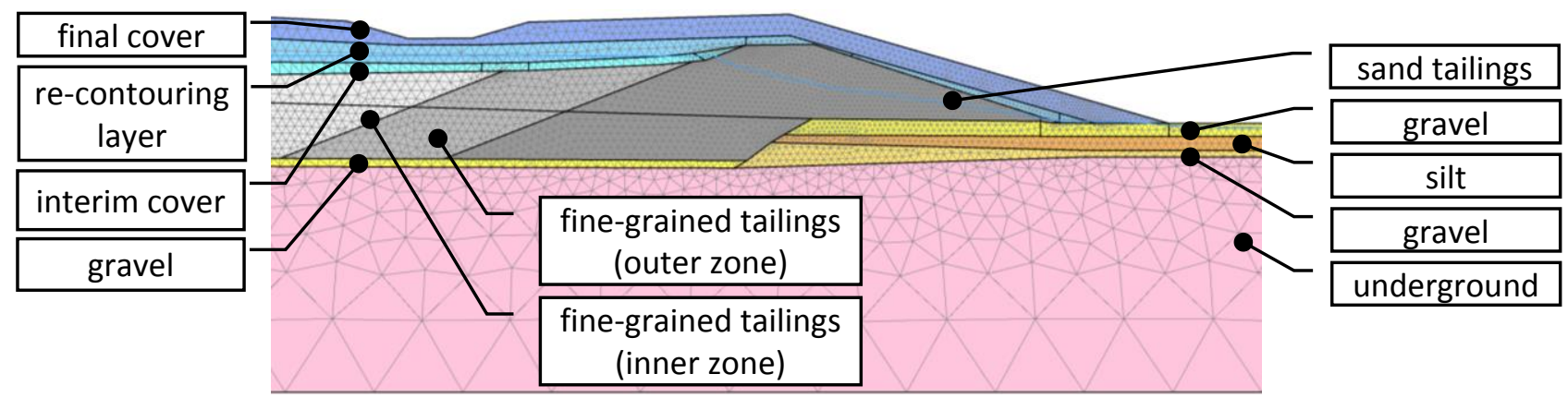

Figure 4 Extract of the numerical cross section 1-1', eastern side of the ring dam (showing the final state), not at scale

The lower model boundaries were defined as fixed and the lateral model boundaries were specified to be freely moveable in the vertical direction and immovable in the horizontal direction. The lateral model boundaries were defined as viscous in the dynamic calculations. Finally, the lower model boundary was coupled with a prescribed displacement on which the motion signal corresponding to the accelerogram was applied.

The groundwater lies approximately $2 \mathrm{~m}$ below the bottom of the tailings. However, the tailings are fully saturated. The supernatant water layer above the tailings surface and precipitation generate a seepage through the ring dam. Seismic loading can cause excess pore water pressure or suction in saturated soils leading to a reduction or increase of the effective shear strength. Therefore the slope stability was analysed considering both, drained and undrained conditions.

\subsection{Soil models and parameters used}

Soils have been modelled using the hardening soil model with small strain stiffness (HSsmall). The HSsmall model is based on the Hardening Soil model (Schanz 1999), extended with an elastic overlay model to take into account the high stiffness at small strain levels (Benz 2007; Benz et al. 2006). The model implemented in PLAXIS considers a high stiffness at small strain levels due to the function of the modulus reduction curve:

$$
G_{S}=\frac{G_{0}}{1+\frac{a \cdot \gamma}{\gamma_{0.7}}}
$$


where: $G_{s}$ is the secant shear modulus, $G_{0}$ is the initial or very small strain shear modulus $G_{0}$ and $\gamma_{0.7}$ is the shear strain at which the secant shear modulus has reduced to about $70 \%$ of $G_{0}$. The constant $a$ is given as 0.385. In the HSsmall Model the very small strain shear modulus $G_{0}$ has a stress dependency, formulated due to:

$$
G_{0}=G_{0}^{r e f}\left(\frac{c^{\prime} \cdot \cot \varphi^{\prime}+\sigma_{3}{ }^{\prime}}{c^{\prime} \cdot \cot \varphi^{\prime}+p^{r e f}}\right)^{m}
$$

$G_{0}$ can be determined by using the correlations between very small stiffness and stiffness at large strains after Alpan 1970. The threshold shear strain $\gamma_{0.7}$ is taken independently of the main stress. It can be defined by using the Mohr-Coulomb failure criterion in Equation (3). For cohesive soils the correlation of Darendeli (2001) could also be used to estimate $\gamma_{0.7}$.

$$
v_{0.7}=\frac{1}{9 G_{0}^{r e f}} \cdot\left[2 c^{\prime}\left(1+\cos \left(2 \varphi^{\prime}\right)\right)-\sigma_{1}^{\prime}\left(1+K_{0}\right) \sin \left(2 \varphi^{\prime}\right)\right]
$$

The HSsmall model shows hysteretic damping within cyclic loading. The damping ratio $\xi$ can be defined by the ratio of the energy dissipated in a load cycle $E_{D}$ to the energy stored at the maximum strain of a load cycle $E_{s}$ :

$$
\xi=\frac{E_{D}}{4 \pi E_{S}}
$$

$E_{D}$ und $E_{S}$ are defined with Equations (5) and (6).

$$
\begin{gathered}
E_{D}=\frac{4 G_{0} \nu_{0.7}}{a} \cdot\left(2 v_{c}-\frac{\gamma_{c}}{1+v_{0.7} / a \nu_{c}}-\frac{2 \gamma_{0.7}}{a} \ln \left(1+\frac{a \gamma_{c}}{\gamma_{0.7}}\right)\right) \\
E_{S}=\frac{G_{0} \nu_{c}^{2}}{2+2 a \nu_{c} / \nu_{0.7}}
\end{gathered}
$$

The magnitude of the cyclic shear strain in which the hysteretic damping exists is defined by:

$$
v_{c} \leq \frac{v_{0.7}}{a} \cdot\left(\sqrt{\frac{G_{0}}{G_{u r}}}-1\right)
$$

where: $G_{u r}$ is the shear modulus in unloading/reloading (Equation 8), which is defined by the stiffness and the Poisson's ratio in unloading/reloading.

$$
G_{u r}=\frac{E_{u r}}{2 \cdot\left(1+v_{u r}\right)}
$$

Brinkgreve et al. 2007 give an extended overview of the derivation of the hysteretic damping from the small-strain stiffness formulation in the HSsmall model. Here the dependency of the damping ratio from $\gamma_{0.7}$ and the $G_{d} / G_{u r}$ ratio is shown due to varying $Y_{0.7}$ in a range of $1 \cdot 10^{-4}$ to $3 \cdot 10^{-4}$ and the $G_{d} / G_{u r}$ ratio in a range of 2.5 to 10. Decreasing the value of $Y_{0.7}$ makes the material damping increase and even increases the ratio of $G d G_{u r}$ (adequate to $E d / E_{u r}$ ) and results in an increase of material damping. From the formulation of the HS small model it can be derived, that no more damping occurs as soon as the tangent shear modulus $G_{t}$ reaches $G_{u r}$.

$$
G_{t}=\frac{G_{0}}{\left(1+a \cdot v / v_{0.7}\right)^{2}} \geq G_{u r}
$$

In addition, according to Brinkgreve et al. (2007), Rayleigh-damping was postulated in the dynamic calculations while these damping parameters were set constant for all layers, which satisfied the requirements of simplification. 


\subsection{Calculation sequence and results}

The history of the development of the tailings pond (excavation from open pit mining, erection of the ring dam, tailings discharge and the rise of the groundwater level) was modelled in order to generate the initial stress state. The ring dam did not show sufficient stability under seismic loading in this state. For this reason the slope of the dam was flattened and inter alia a multi-layer type surface cover was added to reduce the quantity of seepage water, which also had a positive impact on the stability of the slope. This multi-layer type surface cover consists from bottom to top of a $0.5 \mathrm{~m}$ thick sealing layer (hydraulic conductivity $k_{f} \leq 5 \cdot 10^{-9} \mathrm{~m} / \mathrm{s}$ ), an $0.3 \mathrm{~m}$ thick drainage layer (with a grain size distribution granting suffusion stability) and an $1.5 \mathrm{~m}$ thick storage and recultivation layer made of mixed-grained soil.

Figure 5 shows an example of the potential failure mechanism in the static load case for the remediated southern slope of the ring dam of the Dänkritz 2 tailings pond. The calculated global factor of safety is $\eta_{\min }=1.71$.

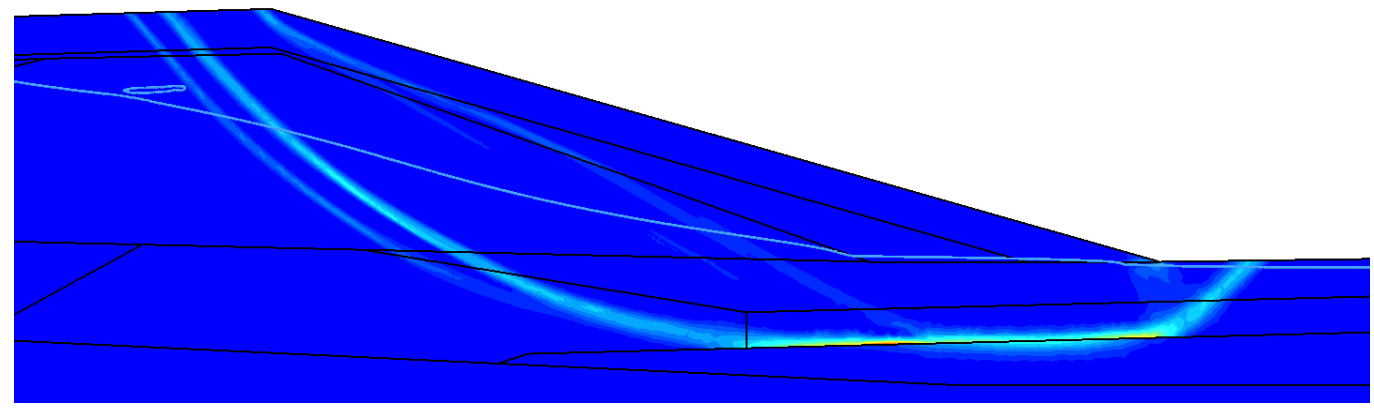

Figure 5 Concentration of deviatoric strain characterising potential failure kinematics of the southern slope in the static load case (final state)

When applying horizontal and vertical acceleration of the safe-shutdown earthquake no continuous sliding surface could be observed by analysing plastic failure points (refer Figure 6a) under provided shear strength. Due to reducing shear strength by 1.1 the calculation model showed an increase in failure points with a tendency towards a continuous sliding surface at the time step 6.6s (refer Figure 6b). Thus, sufficient stability of the ring dam, under seismic loading due to an earthquake, could be proven for the final state with a global factor of safety of $\eta_{\min }>1.10$.

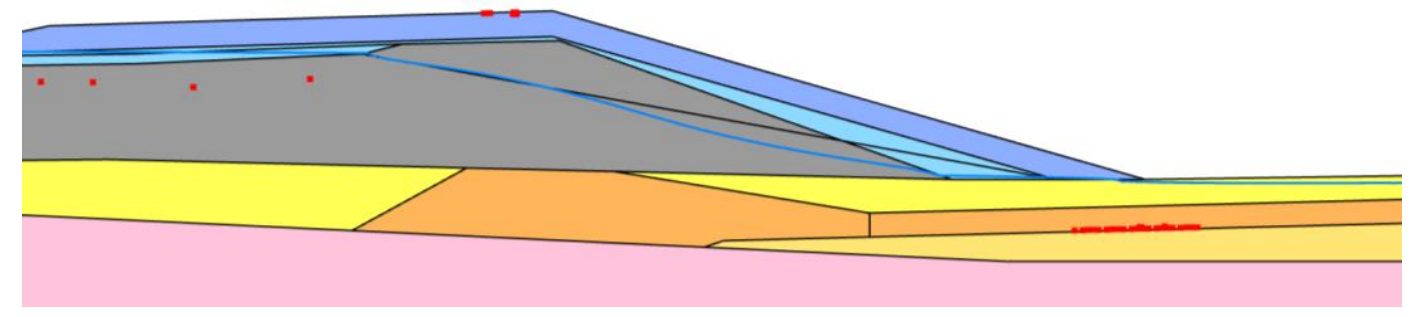

(a)

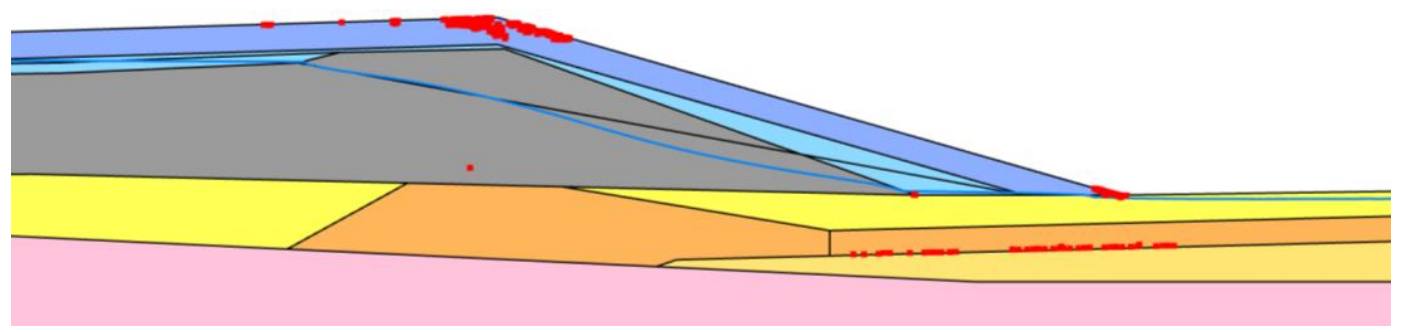

(b)

Figure 6 Development of plastic points due to reduction of shear strength (final state, crucial time step at $6.6 \mathrm{sec}$.): (a) plastic points due to seismic loading; (b) plastic points due to seismic loading, shear parameters reduced by 1.1 


\section{$4 \quad$ Placement of a multi-layer type final cover}

\subsection{Modelling of consolidation}

\subsubsection{Problem definition and boundary conditions}

The behaviour of the soft fine-grained tailings is undrained. When the material is loaded by the multi-layer type surface cover an immediate increase in pore pressure occurs. This excess pore pressure dissipates as water drains from the material very slowly due to its low permeability. As the water drains from the material, change in volume occurs causing settlement (consolidation settlement).

After placing the final cover layer with its water drainage system no more work for regulation shall be done. That means the cover has to be built with a higher level and a pre-defined contour that takes into account the settlement due to the consolidation process.

The thickness of the tailings material in the pond is varying from the ring dam to the centre of the pond between 2 and $12 \mathrm{~m}$, which means that the time needed for the consolidation is quite different in the various locations. While the interim cover has to be built from the ring dam towards the centre of the pond, the re-contouring layers can be placed beginning from the centre of the pond towards the ring dam, allowing the material in the centre to consolidate more quickly. In addition, the dissipation of pore water pressure will be enhanced by means of vertical drains. In order to ensure stability for the used construction equipment a geogrid will be laid out on the surface of the tailings.

The calculation has to consider all these conditions and the model should place Wismut into a position to design the re-contouring work in the right sequence and time, so that the final cover is correctly contoured and the water drainage system is working after completion of consolidation.

\subsubsection{The numerical model}

A three-dimensional finite element calculation using advanced constitutive soil models for the simulation of the non-linear and time-dependent behaviour of tailings has been carried out. The placement of the layers has been modelled by splitting the sequence into calculation phases. The vertical drains and the geogrid have been modelled by means of structure elements. The software PLAXIS was used to implement an undrained effective stress analysis, using effective strength parameters to model the material's undrained shear strength.

The cross-sections from the stability analyses were used. The width (model depth) of the section corresponds to the grid of the vertical drains using the symmetric conditions. Each layer of the interim cover and the re-contouring layer was broken down into individual sections, approximately $10 \mathrm{~m}$ wide, facilitating the simulation of the progress in the construction model. Furthermore, vertical drainage was modelled with a triangular grid spacing of $1.25 \mathrm{~m}$. The vertical drains ended two meters above the bottom of the tailings to prevent drainage into the underground. Figure 7 is an illustration of a section from the calculation model of the right-hand zone of section 1-1' (east side of the basin). Its finite element mesh consists of ten-node tetrahedral elements. This allows second-order interpolation and area integration. To obtain the force, the stiffness matrix and the mass matrix, the tetrahedral elements are integrated with four integration points. The total number of elements is about 124,000 and the average element size is $0.23 \mathrm{~m}$. 


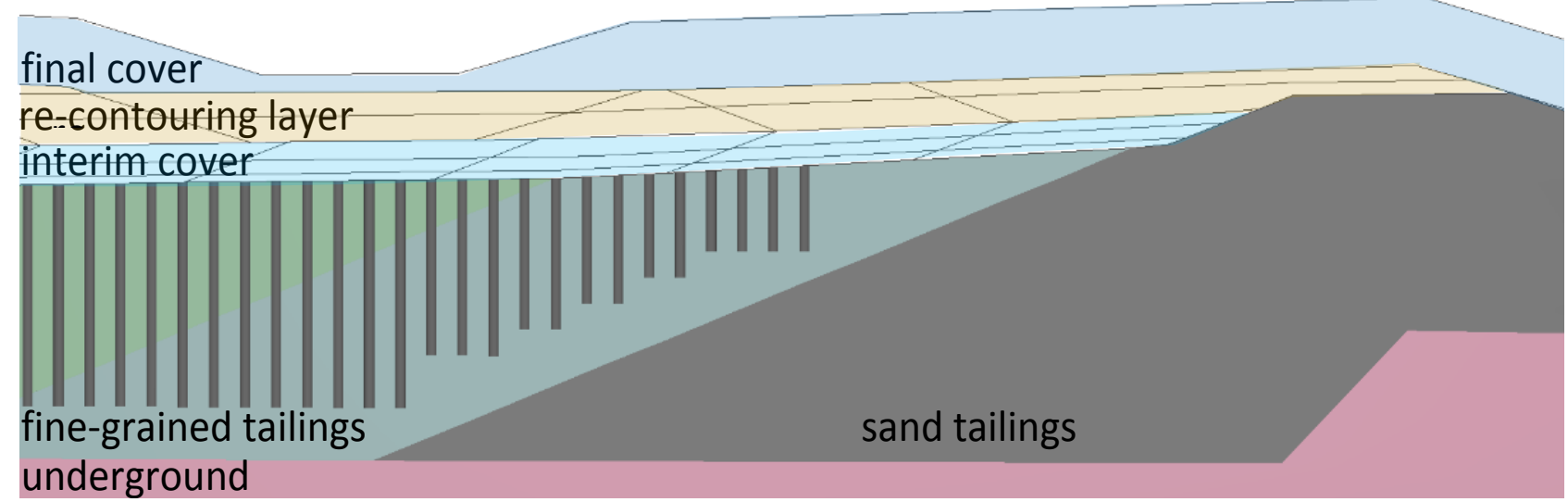

Figure 7 Section used for calculation (cutout - east side of Section 1-1')

\subsubsection{Soil models and parameters used}

The Soft Soil Model was used for this calculation. The model is based on the Cam-Clay model especially meant for primary compression of near normally consolidated clay-type soils. The stress-strain behaviour is described by the relation between the volumetric strain $\varepsilon_{v}$ and the logarithm of the mean effective stress, $\ln \left(p^{\prime}\right)$. These parameters have been derived from standard odometer tests conducted by Wismut using an odometer with $200 \mathrm{~mm}$ internal diameter. Based on a large number of these tests Wismut provided the void-ratio-stress and the void ratio-permeability relations. Furthermore, the depth-dependent, undrained cohesion was measured along profiles by in situ shear vane testing.

The tailings material was discharged in 1955 through 1958 and consolidated under its own weight. The surface settling process and consolidation were verified analytically using a one-dimensional column model and a finite element column model to model the initial stress state of the tailings as close to reality as possible. The void ratio-depth profiles obtained were compared with one another in Figure 8 exemplary for the material of the inner zone of the fine-grained tailings. The void ratios measured in 2014, for depths down to $2 \mathrm{~m}$, are shown here as a reference. The calibrated Soft Soil Model data set is shown in Table 1. Finally, the tailings in the three-dimensional finite element model (refer to Section 4.2) were divided into layers measuring one meter while the void ratio, the specific unit weight and the permeability were postulated in terms of depth here from the calculation of the initial state on the column model (refer to Figure 8).

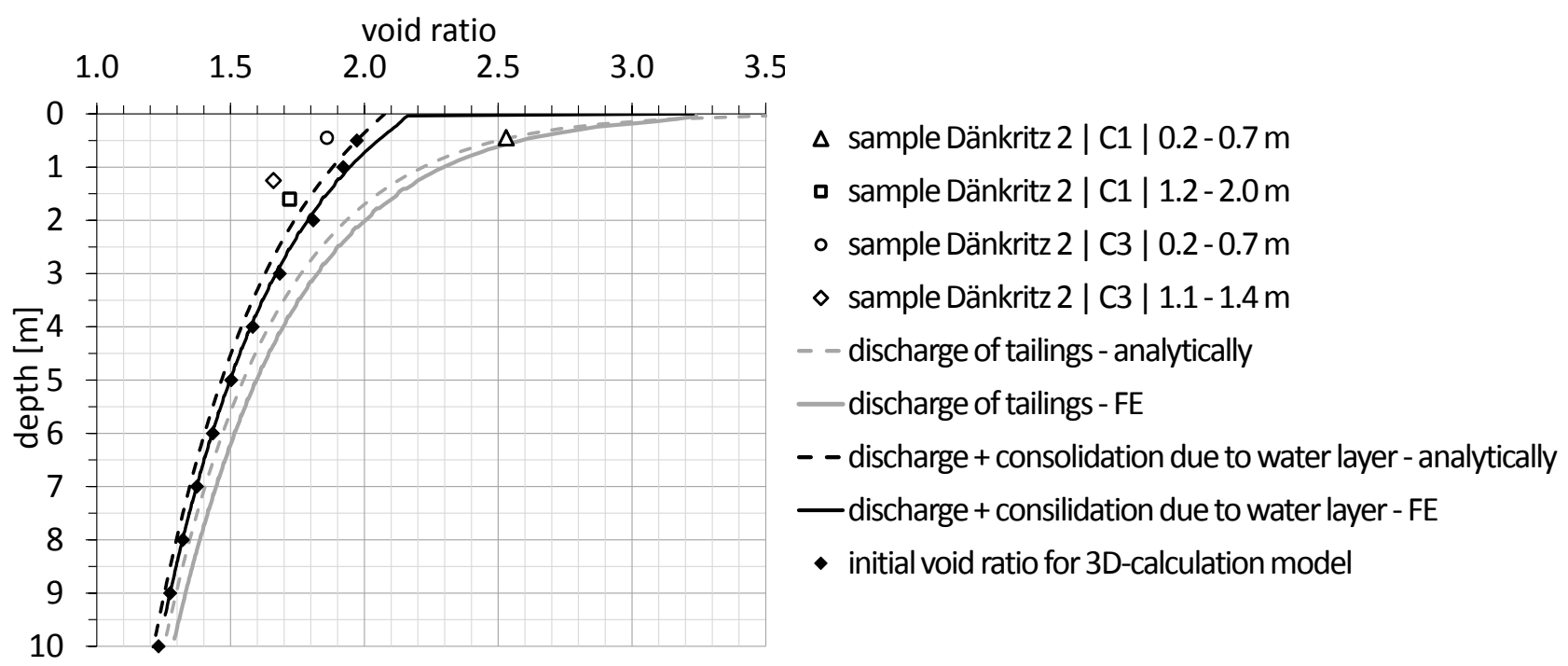

Figure 8 Void ratio depth profile of the inner zone of the fine-grained tailings due simulation of discharge of tailings 
Table 1 Soft soil model data set for the tailings material

\begin{tabular}{lccccc}
\hline \multicolumn{1}{c}{ Parameter } & Symbol & \multicolumn{2}{c}{ Fine-grained tailings } & Unit \\
& & Inner zone & Outer zone & \\
\hline Saturated unit weight (due to change of void ratio) & $\gamma_{\text {sat }}$ & $14.4-22.9$ & $13.4-21.2$ & $\left(\mathrm{kN} / \mathrm{m}^{3}\right)$ \\
\hline Cohesion & $c^{\prime}$ & 0.1 & 0.1 & $\left(\mathrm{kN} / \mathrm{m}^{2}\right)$ \\
\hline Friction angle & $\varphi^{\prime}$ & 7.5 & 10 & $\left(^{\circ}\right)$ \\
Modified compression modulus & $\lambda^{*}$ & 0.088 & 0.080 & $(-)$ \\
Modified swelling modulus & $\kappa^{*}$ & 0.03 & 0.03 & $(-)$ \\
\hline Permeability as function of initial void ratio & $k_{f}(e)$ & $10^{-9} \cdot e^{4.2}$ & $10^{-8} \cdot e^{4.2}$ & $(\mathrm{~m} / \mathrm{s})$ \\
\hline Change of permeability during the change of void ratio & $C_{k}$ & 1 & 0.8 & $(-)$ \\
\hline
\end{tabular}

\subsubsection{Calculation sequence and results}

Consolidation was calculated taking into account the intermediate construction intervals (placement of interim cover, re-contouring layer and final cover). The modelled sequences followed this procedure with the aim to prove that the major portion of settlement due to consolidation will be completed at the end of the re-contouring work. This was essential for the strategy of the construction sequences and construction time. The strategy for the coverage considered an intermediate consolidation phase of each layer.

With completion of the re-contouring layer a maximum settlement of $0.7 \mathrm{~m}$ was calculated in the centre of the pond. The increase of contouring material for compensating this settlement was calculated at approximately $34,500 \mathrm{~m}^{3}$. The additional load of this material was considered in the calculation. Figure 9 shows the progression of the final cover surface after completing the consolidation exemplarily for the eastern side of the tailings pond (right side of cross section $1-1^{\prime}$ ). Position $0.0 \mathrm{~m}$ represents the centre of the tailing pond. At position $90.0 \mathrm{~m}$ the ring dam begins. The dashed curve corresponds to the planned contour while the two other curves show the contour after the completion of consolidation. For the final layer a total settlement of $1.3 \mathrm{~m}$ was calculated at the time step approximately 21 months after completing final coverage. This settlement still ensured the functionality for the planned surface-runoff diversion system and for the drainage system.

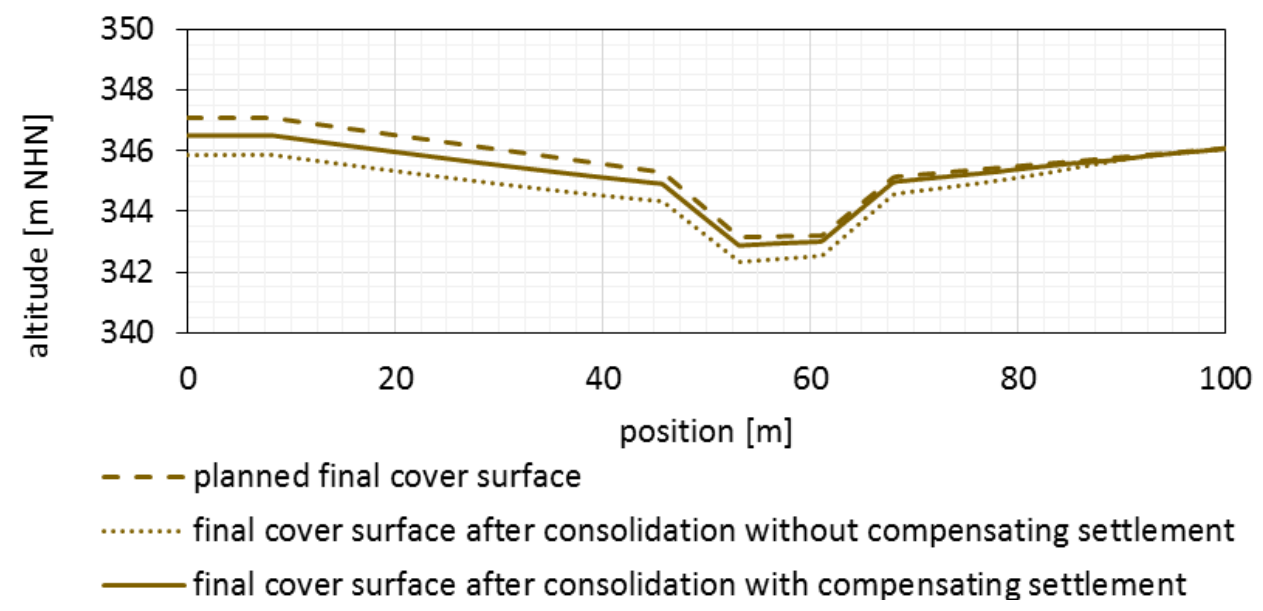

Figure 9 Progression of the final cover surface after completing the consolidation 


\subsection{Stability of the construction equipment}

\subsubsection{Problem definition and boundary conditions}

It is necessary to prevent any ground failure when using construction equipment for interim cover placement, as well as during the following earthworks.

The load of the equipment and the material placed causes an immediate increase in pore pressure along with a reduction of the effective stress, so that the already small shear strength of the material gets even smaller. To ensure stability for the used construction equipment a geogrid will be laid out on the surface of the tailings. The aim of the stability analysis was to prove sufficient load-bearing capacity of the geogrid. This was done pursuant to Eurocode 7 for the ultimate limit state due to the failure of the ground while applying the finite-element method with factored loads. Stability is defined as proven if the finite element model converges in the calculation. That means the equilibrium has to be achieved in the iterative stress calculation. The geogrid was designed for the tensile stress resulting in the calculation, which uses factored loads.

\subsubsection{The numerical model}

The stability of construction equipment on the interim cover was analysed by using a three-dimensional finite element model (Figure 10), where the tailings were divided into layers measuring one meter while the void ratio, the specific unit weight and the permeability were postulated in terms of depth as calculated for the initial state in the column model (refer to Section 4.3). In addition, vertical drains were modelled with a triangular grid spacing of $1.25 \mathrm{~m}$ and a depth of $8 \mathrm{~m}$ including a geogrid on the surface of the tailings. The interim cover has been modelled with its three successively placed layers of thicknesses of $0.3 \mathrm{~m}$ (first layer), $0.5 \mathrm{~m}$ (second layer) and $0.7 \mathrm{~m}$ (third layer).

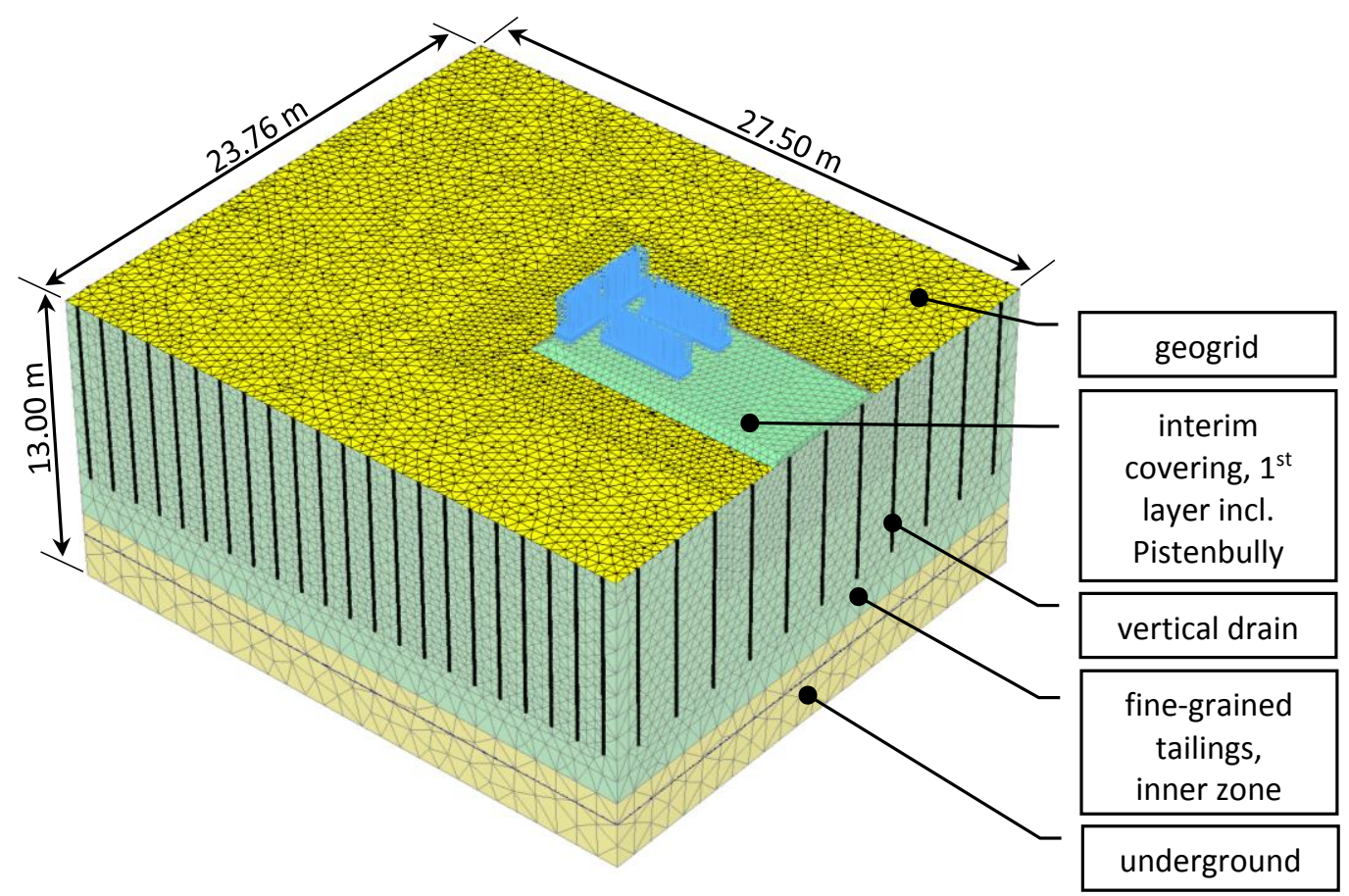

Figure 10 Calculation model for analysing the stability of the construction equipment on interim cover

\subsubsection{Soil models and parameters used}

The Soft Soil Model parameters from the consolidation model were used (see Table 1 in Section 4.3). Figure 11 shows the distribution of the undrained shear strength resulting in the calculation model based on the effective strength parameters. It shows an excellent fit with the very low values measured due to in situ shear vane tests in the upper $3 \mathrm{~m}$ of the tailings, which are relevant for the stability. 


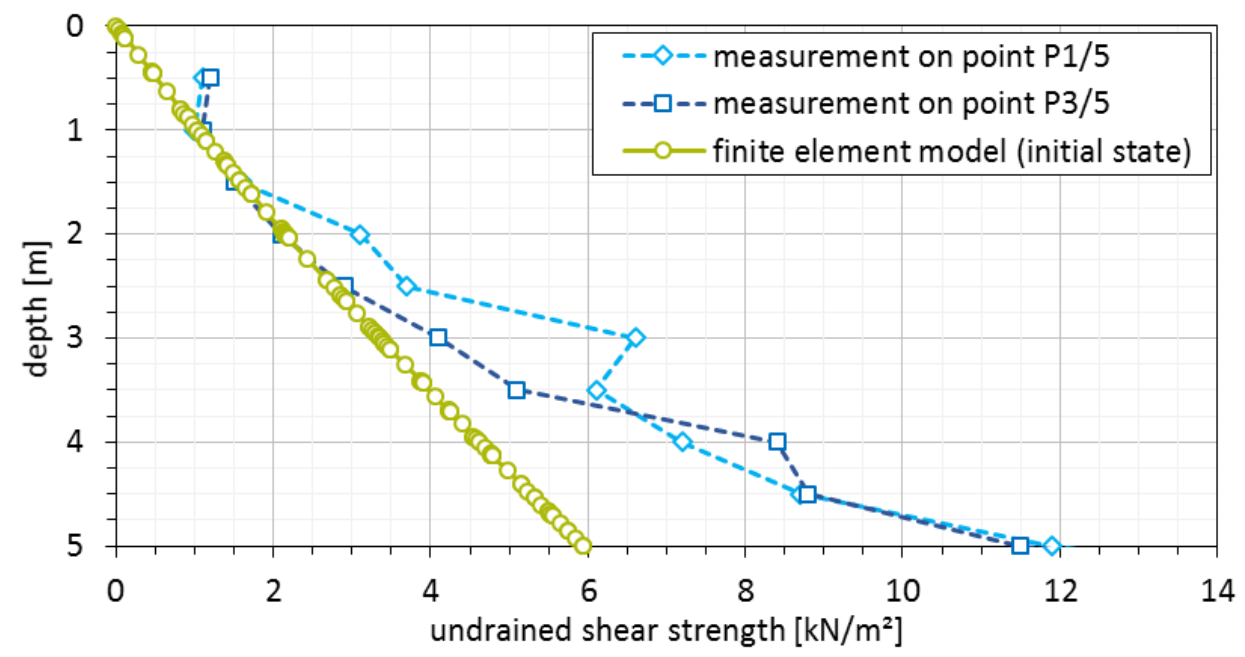

Figure 11 Progression of depth of the undrained shear strength in the fine tailings

An axial tensile stiffness of $700 \mathrm{kN} / \mathrm{m}$ was postulated in finite element modelling for the geogrid design on the surface of the tailings. This value is guided by the SS40 geogrid from Tensar International Limited (2003) that has a resistance to tension of $14 \mathrm{kN} / \mathrm{m}$ at a $2 \%$ strain in the longitudinal and transverse direction of the grid.

\subsubsection{Calculation sequence and results}

The analysis was carried out with the aim to prove the stability of a Pistenbully 300 (Moor caterpillar) and a CAT D3K2 chain dozer. In addition, a stack of soil material was placed in front of the Pistenbully or Dozer considered to impose a surface load of $20 \mathrm{kN} / \mathrm{m}^{2}$. Figure 12 shows the Pistenbully and the geometry postulated in the numerical calculation.
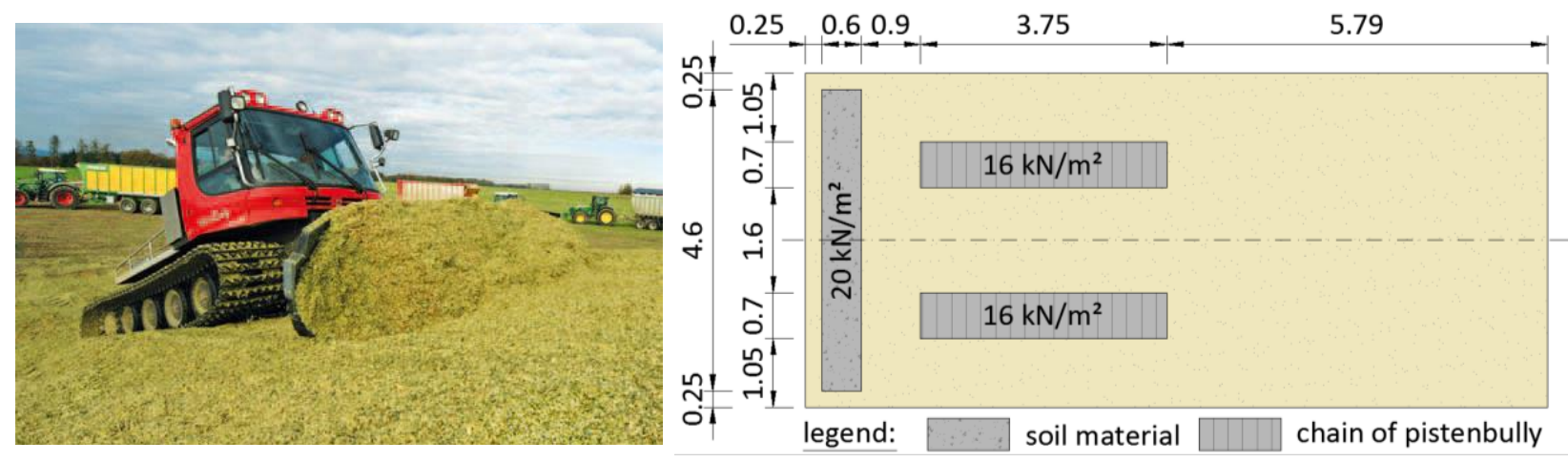

3.75

5.79

Figure 12 Pistenbully 300 and designed load

The assumption made in the calculations was that the entire geogrid and vertical drains had been placed at the beginning of building the 1st layer of interim cover material. Then, the 1st layer was consolidated before building the 2 nd layer, which was included in the calculation with a consolidation time of 60 days. The finished 2 nd layer of the interim cover was also consolidated for 60 days in the calculation before building the 3rd layer. Based on the results of each calculation phase the following conclusions for the build-up process of the interim cover could be given:

- Increase of excess pore water pressure within the tailings.

- Increase of undrained shear strength of the tailings after each phase of consolidation.

- Decrease of differential settlement.

- Decrease in the tensile stress acting upon the geogrid. 
The illustration of the excess pore water pressure shown in Figure 13 indicates the effectiveness of vertical drains during building up the 3 rd layer of the interim cover.

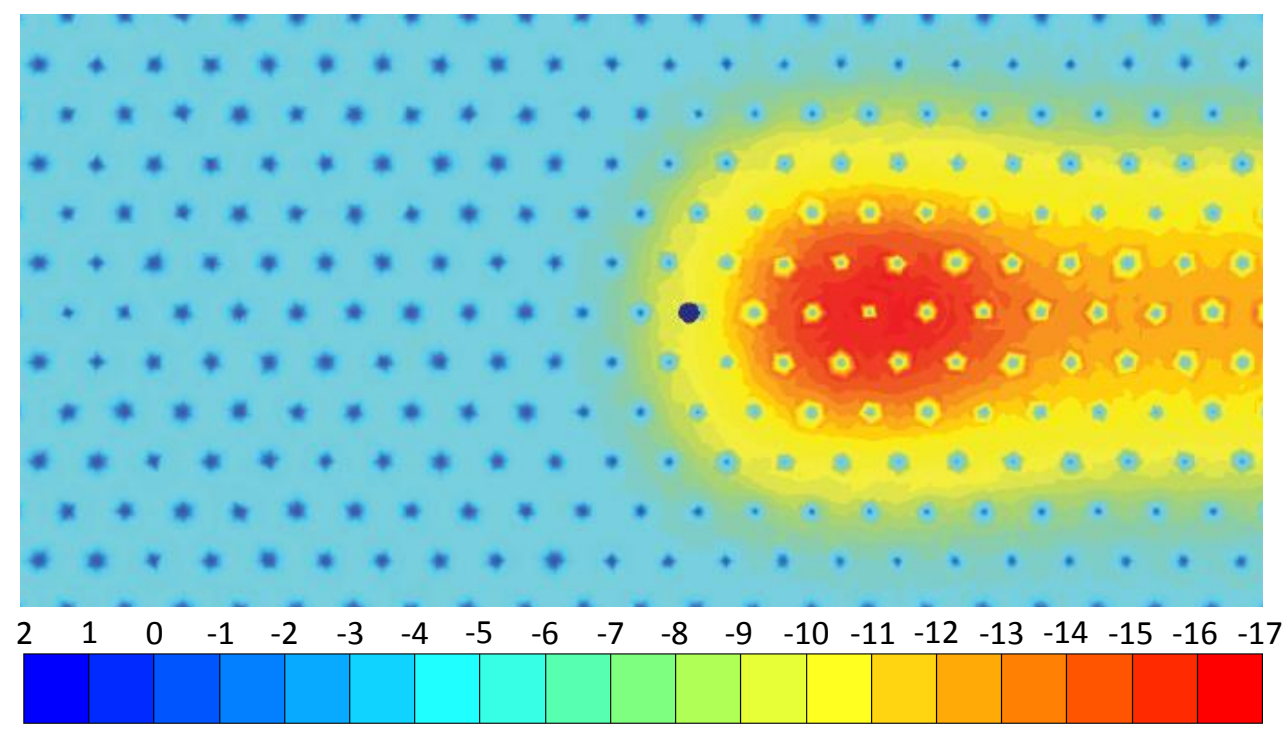

Figure 13 Excess pore water pressure in $\mathrm{kN} / \mathrm{m}^{2}$ during building up the $3 \mathrm{rd}$ layer of the interim cover (horizontal cross section at $1 \mathrm{~m}$ depth below tailing surface)

As expected, the maximum tensile stress $N_{d}$ in the geogrid resulted from the build-up of the 1st layer of the interim cover $\left(N_{d} \approx 11 \mathrm{kN} / \mathrm{m}\right)$. The ground deformation showed a failure behaviour at the 1 st layer of the interim cover, but the calculation converged under factored loads and the analysis of the deviatoric strain (Figure 14) indicated reserves in resistance. The safety of equipment of the equipment could be proven.

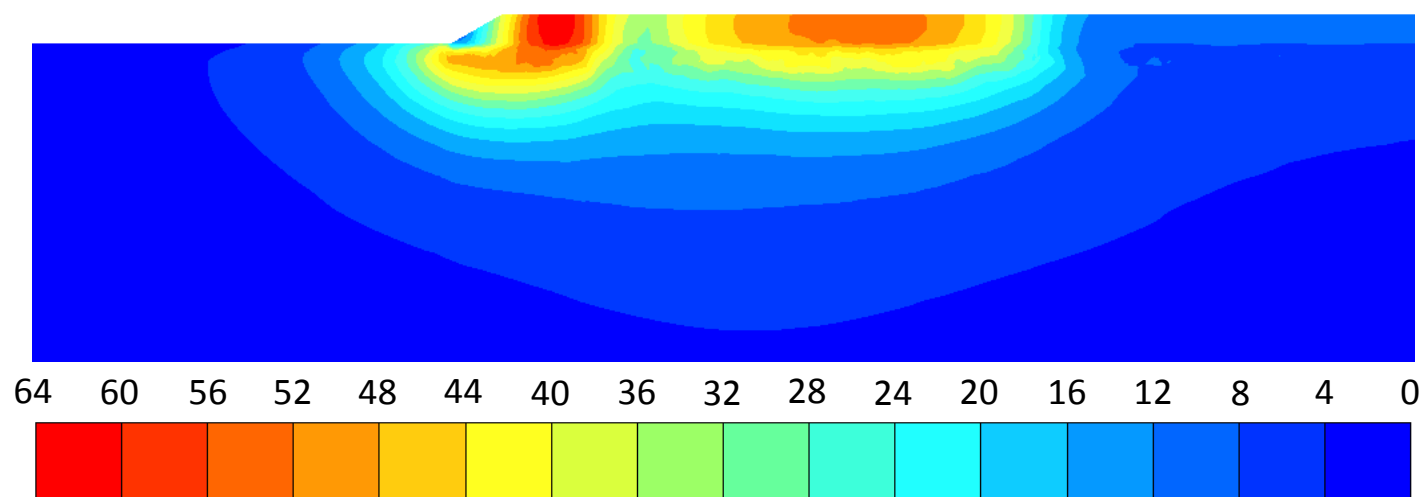

Figure 14 Deviatoric strain $\left(10^{-3} \mathrm{~m}\right)$ due to Build-up of the 1st layer of the interim cover (vertical cross section at chain of Pistenbully)

\section{Conclusion}

The Dänkritz 2 uranium mill tailings pond is one of the abandoned uranium mining sites in Eastern Germany of high priority. The radiological, environmental and geotechnical site assessment proved the need for a site remediation.

Wismut's department for Project Management Saxonian Abandoned Wismut Mining Sites was given the responsibility to manage the project. It designed the tailings remediation project and applied for the respective planning approval in 2015 . The remediation included water collection and treatment during remediation, interim covering of sandy and of soft fine grained tailings, dam reshaping, re-contouring of the pond area enhancing tailings consolidation by using vertical drains, placement of a multi-layer type final cover and vegetation. Geotechnical analyses were carried out by CDM Smith as part of the remediation design. 
In order to analyse the stability of the ring dam under seismic loading CDM Smith performed a fully dynamic calculation using finite element models. Soils have been modelled using the hardening soil model with small strain stiffness, which implements a hysteretic damping. A Rayleigh damping was additionally defined. The calculations were made applying a horizontal and a vertical acceleration of the safe-shutdown earthquake. The factor of safety was determined by repeating the calculations while reducing the shear strength parameters and analysing the development of plastic failure in the system. The ring dam did not show sufficient stability under seismic loading due to an earthquake in its actual state. For this reason the slope of the dam was profiled. Additionally, a multi-layer type surface cover was provided to reduce the quantity of seepage water which had a positive impact on the stability of the slope. Sufficient stability of the ring dam under seismic loading could be proven for the final state with a global factor of safety of $\eta_{\min }>1.10$.

In order to place Wismut into a position to design the re-contouring work in the right sequence and time, such that the final cover lies in correct contour and the water drainage system is working after completion of consolidation of the tailings, CDM Smith carried out a three-dimensional finite element calculation using advanced constitutive soil models for the simulation of the non-linear and time-dependent behaviour of the tailings. The parameters used for the soil model have been calibrated in one-dimensional models based on results from laboratory and field investigations. The modelled sequences followed the procedure of the construction with the aim to prove that the major portion of settlement due to consolidation will be completed at the end of the re-contouring works. This was essential for the design strategy of the construction sequences and construction time. For the final state a total settlement of $1.3 \mathrm{~m}$ was calculated at the time step approximately 21 months after completing the final surface cover. This settlement still ensured the functionality of the planned surface runoff diversion system and the drainage system within the surface cover.

It is necessary to prevent any ground failure when using construction equipment for successive placement of the interim cover on the tailings. This is accomplished by installing an underlying geogrid. The aim of the stability analysis carried out by CDM Smith was to prove sufficient load-bearing capacity of the geogrid. This was done pursuant to Eurocode 7 while applying the finite-element method with factored loads. Stability has been proven as the finite element model converged in the calculation. The geogrid was designed for the tensile stress resulting in the calculation, using factored loads.

\section{References}

Alpan, I 1970, 'Geotechnical properties of soils', Earth-Science Reviews, rev. 6, pp. 5-49.

Benz, T 2007, 'Small Strain stiffness of soils and its numerical consequences', PhD thesis, University of Stuttgart.

Benz, T, Schwab, R \& Vermeer, PA 2006, 'A small strain overlay model, I: model formulation', International Journal for Numerical and Analytical Methods in Geomechanics, vol. 33, no. 1, pp. 25-44.

Brinkgreve, RBJ, Kappert, MH \& Bonnier, PG 2007, 'Hysteretic damping in a small-strain stiffness model', in GN Pande \& S Pietruszczak (eds), Numerical Models in Geomechanics, Taylor \& Francis Group, London.

Darendeli, MB 2001, 'Development of a New Family of Normalized Modulus Reduction and Material Damping Curves', PhD thesis, Department of Civil Engineering, The University of Texas at Austin.

DIN 19700-15 2004-07, 'Stauanlagen, Teil 15 - Sedimentationsbecken'.

DIN 4149 2005-04, 'Bauten in deutschen Erdbebengebieten - Lastannahmen, Bemessung und Ausführung üblicher Hochbauten' (replaced by DIN EN 1998-1/NA 2011-01).

DIN EN 1998-1 2010-12, 'Eurocode 8 - Auslegung von Bauwerken gegen Erdbeben - Teil 1: Grundlagen, Erdbebeneinwirkungen und Regeln für Hochbauten'.

DIN EN 1998-1/NA 2011-01, 'Nationaler Anhang - National festgelegte Parameter - Eurocode 8: Auslegung von Bauwerken gegen Erdbeben - Teil 1: Grundlagen, Erdbebeneinwirkungen und Regeln für Hochbau'.

Fellenius, WKA 1936, 'Calculation of the Stability of Earth Dams', in Transactions of the Second Congress on Large Dams, Washington DC, 4, pp. 445-462.

Schanz, T, Vermeer, PA \& Bonnier, PG 1999, 'Formulation and verification of the Hardening-Soil Model', in RBJ Brinkgreve, Beyond 2000 in Computational Geotechnics, Balkema, Rotterdam, pp. 281-290.

Tensar International Limited 2003, The Properties and Performance of Tensar Biaxial Geogrids, Tensar SS geogrid specifications Issue 3, 79010055. 